\title{
Experimental research on modal parameter identification of 100-meter fully-grouted reinforced-block masonry shear wall structure
}

\author{
Zhao Yan ${ }^{1,2, a}$, Chen Siyuan ${ }^{1, b}$, Li Huaming ${ }^{1, c}$ and Liu Hongbo ${ }^{3, d}$ \\ ${ }^{1}$ School of Civil Engineering and Architecture, Jiamusi University, Jiamusi 154007,China \\ ${ }^{2}$ Key Laboratory of Earthquake Engineering and Engineering Vibration, Institute of Engineering \\ Mechanics, China Earthquake Administration, Harbin 150080,China \\ ${ }^{3}$ School of Civil Engineering and Architecture, Heilongjiang University, Harbin 150080,China \\ azhaoyan_hit@163.com, ${ }^{b}$ chensy@163.com, ${ }^{c}$ Ihm_91@sina.com, 'hliu@hlju.edu.cn
}

Keywords: Fully grouted reinforced-block masonry shear wall structure; Modal parameter identification; Ambient excitation; Velocity time-history; Fourier spectra

Abstract. To evaluate the dynamic characteristics of 100-meter fully-grouted reinforced-block masonry shear wall (FG-RMSW) structure, a FG-RMSW structure in construction process was tested using the ambient excitation vibration method. A total of three tests were conducted to fully understand the dynamic characteristics of this structure. Based on the structural characteristics, when the structure was built to the 10th, the 18th, and the 28th floor respectively, translation in transversal, longitudinal, and vertical directions and the vertical rotation of the structure were tested. Multiple velocity time-history and acceleration time-history records of the structure were obtained through tests. Moreover, Fourier spectra of the structure in different directions at different heights were calculated. The test results indicated that the velocity time-history was stable, without an excessive fluctuation and pulse; the reliable data could be obtained through the filtering method. Therefore, it is recommended that the velocity time-history is used as the object of analysis. By picking up the peak in the Fourier spectra, the fundamental frequencies of the structure on the 10th, the 18th, and the 28th floor were $2.76 \mathrm{~Hz}, 1.18 \mathrm{~Hz}$ and $0.63 \mathrm{~Hz}$ respectively. The higher the height of the structure, the more abundant the frequencies-spectra components are, and the higher-order modes of the structure can be displayed. The dynamic characteristics of such structures can be obtained by adopting the modal parameter identification method under ambient excitation.

\section{Introduction}

According to the time of load action and the number of repeated actions, the structural dynamic tests can be divided into the following categories: explosion or impact load test, structural seismic test-seismic modeling shaking table test, structural fatigue test and structural vibration test. There are two types of vibration tests in the structure, one is the vibration generated in industrial processes and the other is the vibration generated by natural factors. The structural dynamics analysis based on ambient vibration test has important significance both in the engineering application and in the academic research. It is a hot topic in the field of structural engineering [1-5]. The measured structural dynamic characteristics are the premise and basis of structural seismic analysis, structural damage identification, assessment of damaged structures, structural control and structural real-time monitoring, and can also be used to verify the accuracy of the finite element model. The modal parameter identification method under ambient excitation has a great practical value, and covers a wide range of applications in the fields of national defense, transportation, machinery, civil engineering, and aerospace [6-7]. The utilization of vibration caused by ambient excitation has many advantages in identifying modal parameters of a structural system. For example, it does not need an expensive excitation set, saves testing time, does not affect the normal use of the structure, does not cause any damage to the structure, only needs to measure the response data and the like, therefore, it has aroused a wide concern among domestic and foreign researchers in the civil engineering sector[8]. In this paper, an actual project was taken as the research object, and the structure modal parameter identification method under the ambient excitation was used for carrying out three tests in the construction stage of 
the structure. The velocity time-histories of the structure at different heights were obtained and the frequency spectra were analyzed to obtain the Fourier spectra in X direction, Y direction, and torsion direction. The results obtained in this paper can provide the experimental basis for the dynamic characteristics analysis of high-rise fully-grouted reinforced-block masonry shear wall structure system and provide technical support for the development of such system for high-rise and super-high-rise buildings

\section{Project Overview}

The structure is located in Songbei District, Harbin, China and it is the first fully-grouted reinforced-block masonry shear wall (FG-RMSW) structure more than 100 meters high. The standard plan of this structure is as shown in Fig. 1. The structure has 28 floors above the ground and 1 floor underground, with the total construction area of $16,187 \mathrm{~m} 2$, the basement is $5.0 \mathrm{~m}$ high, the ground floor is $4.5 \mathrm{~m}$ high, the second floor is $4.2 \mathrm{~m}$ high, the standard floor is $3.4 \mathrm{~m}$ high and the 28th floor is $4.5 \mathrm{~m}$ high. The staircase and the elevator room are out of roof, with the height of $3.6 \mathrm{~m}$. The cornice elevation is $98.2 \mathrm{~m}$ high, and the height of the elevator room is $101.8 \mathrm{~m}$. The types of fully-grouted reinforced-blocks used in the structure are as follows: the standard blocks with dimensions of $390 \mathrm{~mm}$ $(\mathrm{L}) \times 190 \mathrm{~mm}(\mathrm{H}) \times 290 \mathrm{~mm}(\mathrm{~W})($ referred to as Block 290) are used for the 1st floor to the 12th floor; the standard blocks with dimensions of $390 \mathrm{~mm}(\mathrm{~L}) \times 190 \mathrm{~mm}(\mathrm{H}) \times 190 \mathrm{~mm}(\mathrm{~W})$ (referred to as Block 190) are used for the 15th floor to the 28th floor; the 13th floor and the 14th floor are transition floors, using Block 290 for the exterior wall and Block 190 for the interior wall, and the hole rates of Block 290 and Block 190 are 53\% and 45\% respectively. The strength grades of Block 290 and Block 190 are both MU20 and their mortar strength grade is Mb20. Both types of the blocks use the $100 \%$ full-grouted with $\mathrm{C} 40$ concrete. The building site for the construction is of Class III and the first earthquake group, with seismic fortification intensity of 6 degrees.

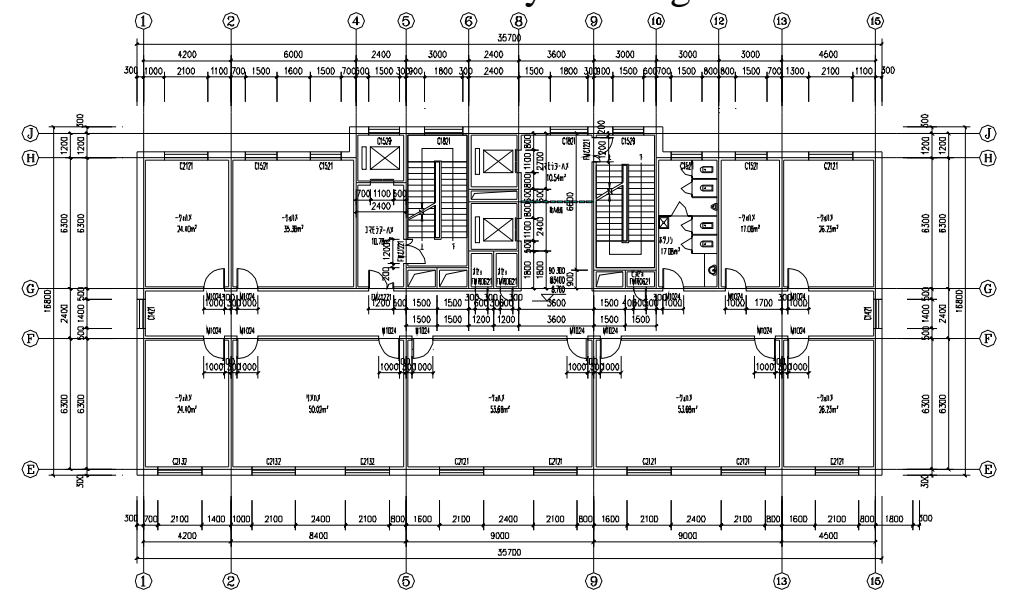

Fig. 1 Standard Floor Plan of $3^{\text {rd }}-27^{\text {th }}$ Floor

\section{Ambient Vibration Test}

The ambient vibration test is also known as ambient random excitation, or ambient pulsation method. The overall structure being the test object is used to determine the dynamic characteristics of the structure through the linear modal parameter identification by using the impulse response of the structure caused by the ambient random vibration and applying the vibration inversion theory ${ }^{[9-11]}$. The process of the ambient vibration test is as shown in Fig. 2. Under the excitation of the natural environment, the modal parameter identification is the system identification based on the output response only. At present, researchers at home and abroad have proposed a variety of modal parameter identification methods, mainly including two major categories, i.e. frequency domain methods, such as Peak Picking Method (PP), Frequency Domain Decomposition (FDD), and Enhanced Frequency Domain Decomposition (EFDD); and time domain methods, such as Eigensystem Realization 
Algorithm (ERA), Random Decrement Technique, NExT (Natural Excitation Technique), Modal Function Decomposition, Stochastic Subspace Algorithm (SSI), and Time Series Method[3-5]. Each of these methods has its own advantages and disadvantages. In practice, multiple methods may be used for calculation and checking, so as to obtain the accurate dynamic characteristic parameters of the structure.

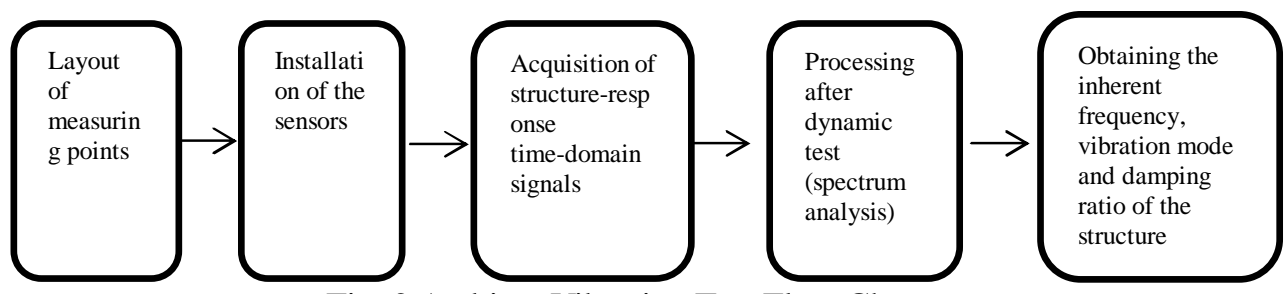

Fig. 2 Ambient Vibration Test Flow Chart

\section{Test Instruments and Devices}

The data acquisition system for the field test mainly includes data acquisition instruments, charge amplifiers and uniaxial force balance accelerometers, as well as a laptop, as shown in Fig. 3. The uniaxial force balance accelerometer uses the 941B ultra-low frequency passive servo pickup (horizontal and vertical), as shown in Fig. 4, and the main technical indicators are given in Table 1. The charge amplifier is the corresponding 941-type amplifier. Prior to the field test, the accelerometer was first calibrated for the purpose of eliminating or minimizing the difference between accelerometer characteristics and the influence of the connecting cables on the test signal. For the same type of accelerometers, there will be a difference between accelerometers even if they are connected to the same cable and the same input state. Calibration tests include the conformance test and the sensitivity test. We adopt the conformance test where all accelerometers are placed close to one another, a sine wave is input, a simultaneous recording is performed, and the amplitudes are adjusted to calibrate each accelerometer according to its sensitivity.

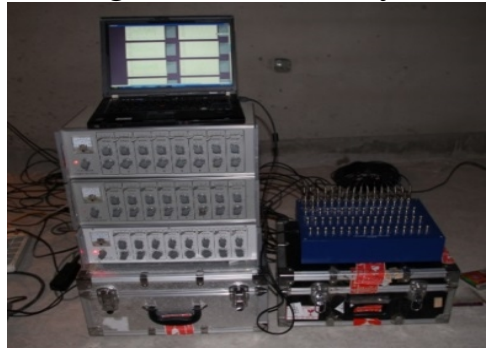

Fig. 3 Data acquisition system

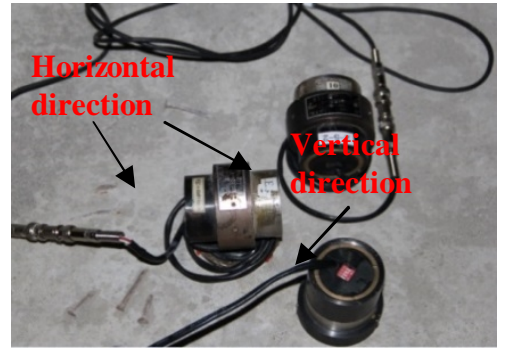

Fig. 4 941B accelerometer

Table1 Parameters of an Accelerometer

\begin{tabular}{|c|c|c|c|c|c|}
\hline \multicolumn{2}{|c|}{ Technical indicators } & Acceleration & $\begin{array}{l}\text { Minimum } \\
\text { velocity }\end{array}$ & $\begin{array}{l}\text { Medium } \\
\text { velocity }\end{array}$ & $\begin{array}{l}\text { Maximum } \\
\text { velocity }\end{array}$ \\
\hline Sensitivity & {$\left[\mathrm{Vs} / \mathrm{m}\right.$ or $\left.\mathrm{Vs}^{2} / \mathrm{m}\right]$} & 0.3 & 25 & 2.5 & \multirow{4}{*}{$\begin{array}{l}\quad 0.8 \\
\text { Maximum } \\
\text { range }\end{array}$} \\
\hline \multirow{3}{*}{ Maximum range } & Acceleration $\left[\mathrm{ms}^{-2}\right]$ & 20 & - & - & \\
\hline & Velocity $\left[\mathrm{ms}^{-1}\right]$ & - & 0.125 & 0.3 & \\
\hline & Displacement [mm] & - & 20 & 200 & \\
\hline Pass band & {$[\mathrm{Hz}]$} & $0.25-80$ & $1-100$ & $0.25-100$ & $0.17-100$ \\
\hline \multicolumn{2}{|c|}{ Output load resistance $\quad(\mathrm{k} \Omega)$} & 1 & 1 & 1 & \multirow{4}{*}{$\begin{array}{c}1 \\
\text { Resolution }\end{array}$} \\
\hline \multirow{3}{*}{ Resolution } & Acceleration $\left[\mathrm{ms}^{-2}\right]$ & $5 \times 10^{-6}$ & - & - & \\
\hline & Velocity $\left[\mathrm{ms}^{-1}\right]$ & - & $4 \times 10^{-8}$ & $4 \times 10^{-7}$ & \\
\hline & Displacement [mm] & - & $4 \times 10^{-8}$ & $4 \times 10^{-7}$ & \\
\hline \multicolumn{3}{|l|}{ Size and weight } & \multicolumn{3}{|c|}{$65 \mathrm{~mm} \times 65 \mathrm{~mm} \times 85 \mathrm{~mm} 1.0 \mathrm{~kg}$} \\
\hline
\end{tabular}

\section{Instrument Arrangement and Test Program}

The instruments were arranged at the floor of the antechamber between the stairwell and the 
elevator shaft, where the stiffness is greater, the disturbance factors are relatively less, and the noise in the signal is relatively weaker. On the one hand, due to the large number of floors and the limited number of sensors, it is not possible to arrange measuring points on each floor; on the other hand, it is not necessary to arrange measuring points on each floor according to the theoretical analysis, due to the structure is relatively regular and plane symmetric. Therefore, the sensors were arranged only on the selected representative floors. When the measuring structure was in translation, three sensors were installer for each measuring point, as follows: a transverse acceleration sensor was arranged along the transverse direction ( $\mathrm{X}$ direction) and the longitudinal direction ( $\mathrm{Y}$ direction) of the structure, respectively, to measure the translation in the $\mathrm{X}$ direction and the $\mathrm{Y}$ direction. At the same time, a vertical acceleration sensor was arranged to measure the vertical translation as shown in Fig. 5-(a). When the measurement structure is twisted, the transverse sensors are correspondingly placed on both ends of the structure, and along the Y direction. See Figure 5-(b) below for the specific locations of the sensors.

The whole structure has a total of 28 floors. The testing process was divided into three phases. When the structure was constructed to the $10^{\text {th }}$, the $18^{\text {th }}$, and the $28^{\text {th }}$ floor respectively, the ambient vibration test was conducted to test the vibration mode and the frequency of the structure. The test involved an $\mathrm{X}$-direction translation, a Y-direction translation, a Z-axis rotation, and a vertical vibration. In the three tests, the specific floors with the sensors arranged were as follows: five floors for the first time, i.e. $1^{\text {st }}$, $3^{\text {rd }}, 5^{\text {th }}, 7^{\text {th }}$ and $10^{\text {th }}$ floor; seven floors for the second time, i.e. $1^{\text {st }}, 4^{\text {th }}, 7^{\text {th }}, 10^{\text {th }}, 13^{\text {th }}, 16^{\text {th }}$ and $18^{\text {th }}$ floor; and nine floors for the third time, i.e. $1^{\text {st }}, 5^{\text {th }}, 9^{\text {th }}, 12^{\text {th }} 14^{\text {th }}, 15^{\text {th }}, 19^{\text {th }}, 23^{\text {rd }}$ and $28^{\text {th }}$ floor, respectively. Considering that $290 \mathrm{~mm}$ blocks were used in the first floor through the $12^{\text {th }}$ floor, $190 \mathrm{~mm}$ blocks were used in the floors above the $15^{\text {th }}$ floor, $290 \mathrm{~mm}$ blocks were used for the external walls vs. $190 \mathrm{~mm}$ blocks for the internal blocks in the $13^{\text {th }}$ floor through the $14^{\text {th }}$ floor, the measuring points were arranged on the $12^{\text {th }}$ floor, the $14^{\text {th }}$ floor, and 15 th floor respectively, in order to test the changes of mechanical properties of the transitional floors of the structure. The pulsation response of a structure caused by the ambient random vibration test requires that the acquired data should be of sufficient length to describe the average characteristics of all samples by using a single sample function's time. Therefore, in each test of this experiment, the pulsation data acquisition time was more than 10 minutes, meeting the requirements of the ambient vibration test. In order to avoid interference from the external environment, the tests were conducted in the evening when all construction works were stopped.

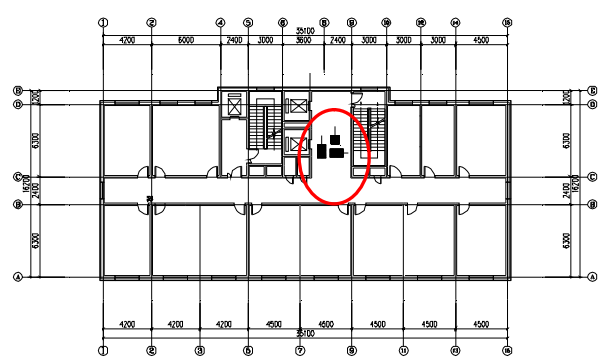

(a) Testing the translation of the structure

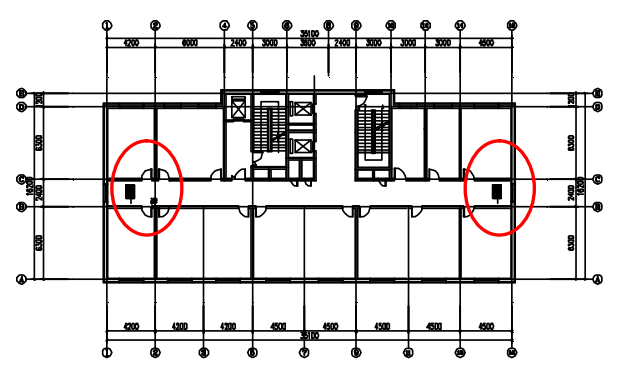

(b) Testing the torsion of the structure

Fig. 5 Sensor Positions and Measuring Directions

\section{Test Results Analysis}

The acceleration time-history and velocity time-history were tested in the field respectively. By comparison, it was determined that the velocity time-history was more stable. Therefore, the velocity time-history was used to analyze the results of the three tests. The test process involved two working conditions: the first one was the translation of the test structure, for which, the test was carried out in the $\mathrm{X}$ direction, the $\mathrm{Y}$ direction, and the vertical direction of the structure; and the second one was the rotation of the test structure around the $\mathrm{Z}$ axis. Each working condition was tested more than twice. Due to the large number of tests and measuring points, only the velocity time-histories of the translation in the $\mathrm{X}$ direction, the $\mathrm{Y}$ direction, and the rotation around the $\mathrm{Z}$ axis are listed in this paper, 
as shown in Fig. 6, where the velocity time-histories of the top floor in the three tests are provided. From the figure, it can be seen that the velocity time-histories are relatively uniform and there is no excessive fluctuation or pulse, indicating that the test was relatively stable, with lower interference from the external environment and being able to reflect the structure's own characteristics.
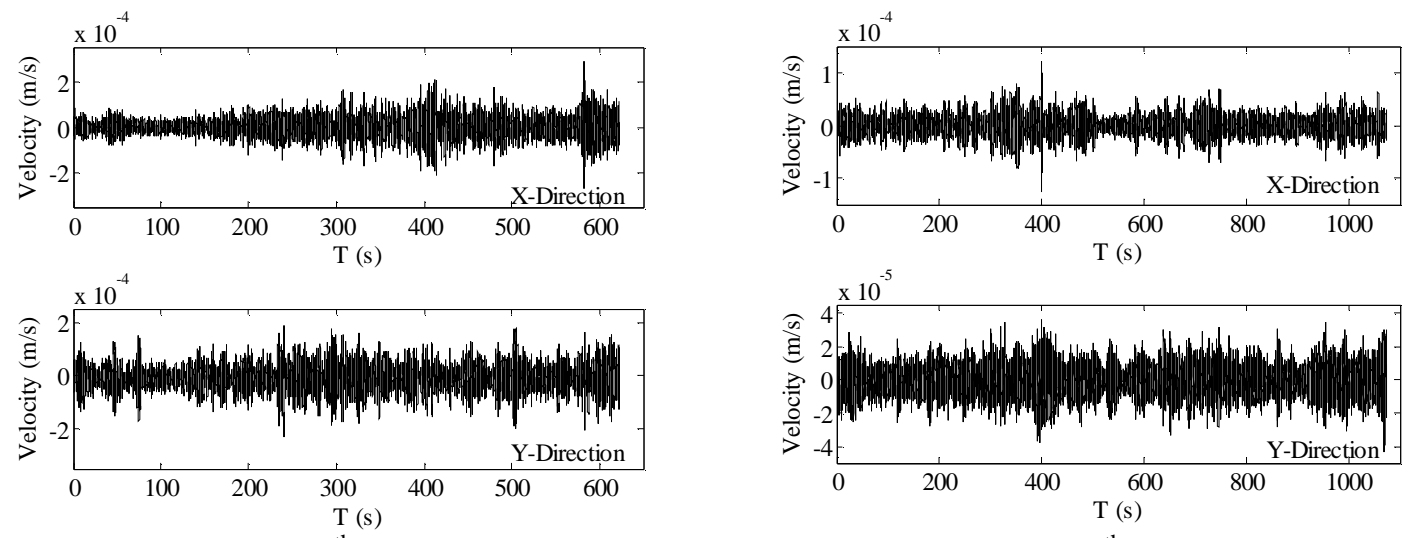

(a) the $10^{\text {th }}$ floor

(b) the $18^{\text {th }}$ floor
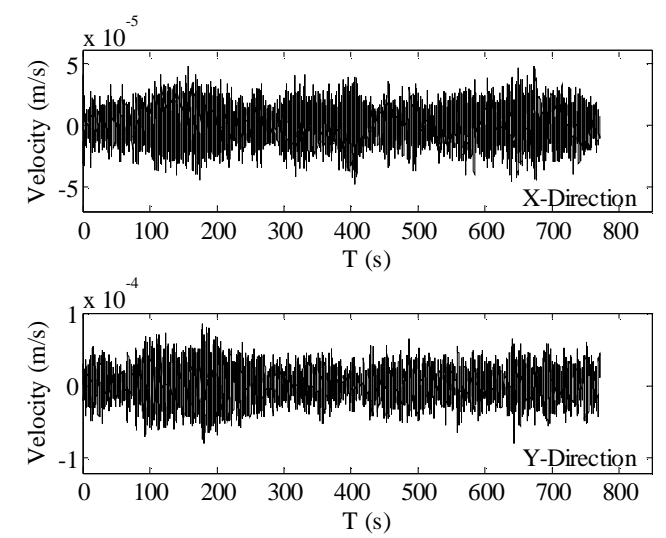

(c) the $28^{\text {th }}$ floor

Fig. 6 Velocity Time-histories

\section{Frequency Spectra}

The frequency spectra analysis was carried out on the velocity time-history to calculate the Fourier spectrum of each measuring point. The Fourier spectra and the Power spectra in the X direction, the $Y$ direction, and the Z-axis rotation of the top floor in the three tests are shown in Fig. 7. From the figure, it can be seen that the corresponding amplitudes of some peaks in Fourier spectra are very large, and correspond to certain frequencies of the structure. In the second test, two peaks can be clearly seen in the Fourier spectra of the $18^{\text {th }}$ floor, corresponding to the second-order frequencies of the structure. In the third test, the spectral patterns of the Fourier spectrum of the $28^{\text {th }}$ floor became more abundant, showing higher order modes. Different order modes of the structure may be obtained by using the modal parameter identification method. Through calculation, the fundamental frequencies of the structure in the $10^{\text {th }}$, the $18^{\text {th }}$, and the $28^{\text {th }}$ floor were obtained, namely $2.76 \mathrm{~Hz}, 1.18 \mathrm{~Hz}$ and $0.63 \mathrm{~Hz}$ respectively. It can be seen that, the frequency of the structure decreases as the height of the structure increases, but the decrease is not linear. 

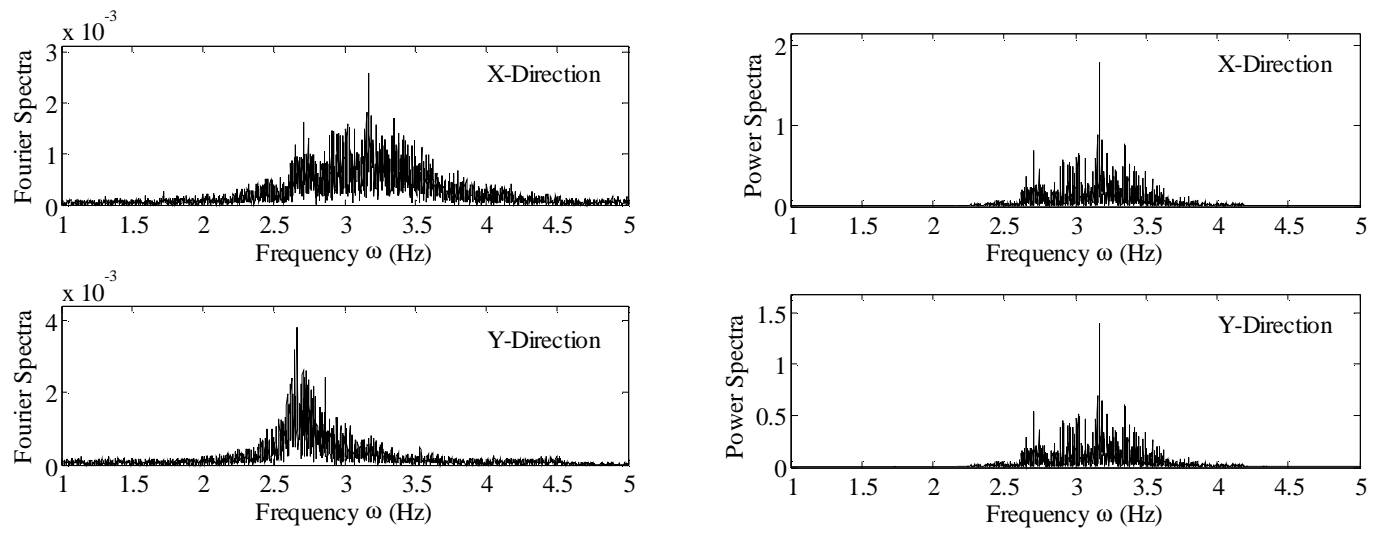

(a) the $10^{\text {th }}$ floor
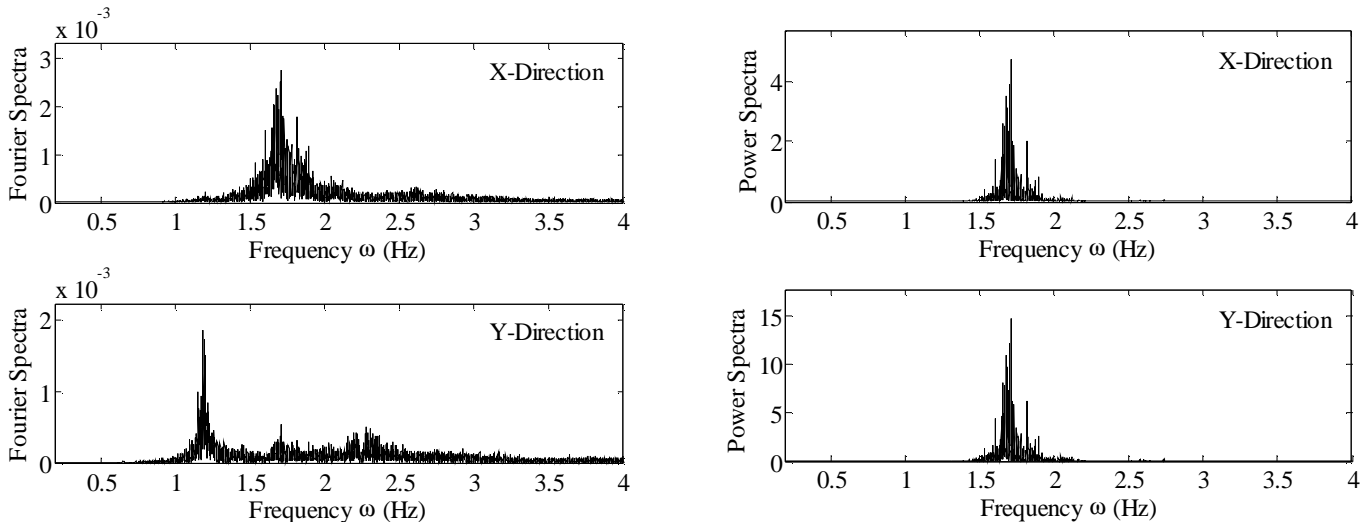

(b) the $18^{\text {th }}$ floor
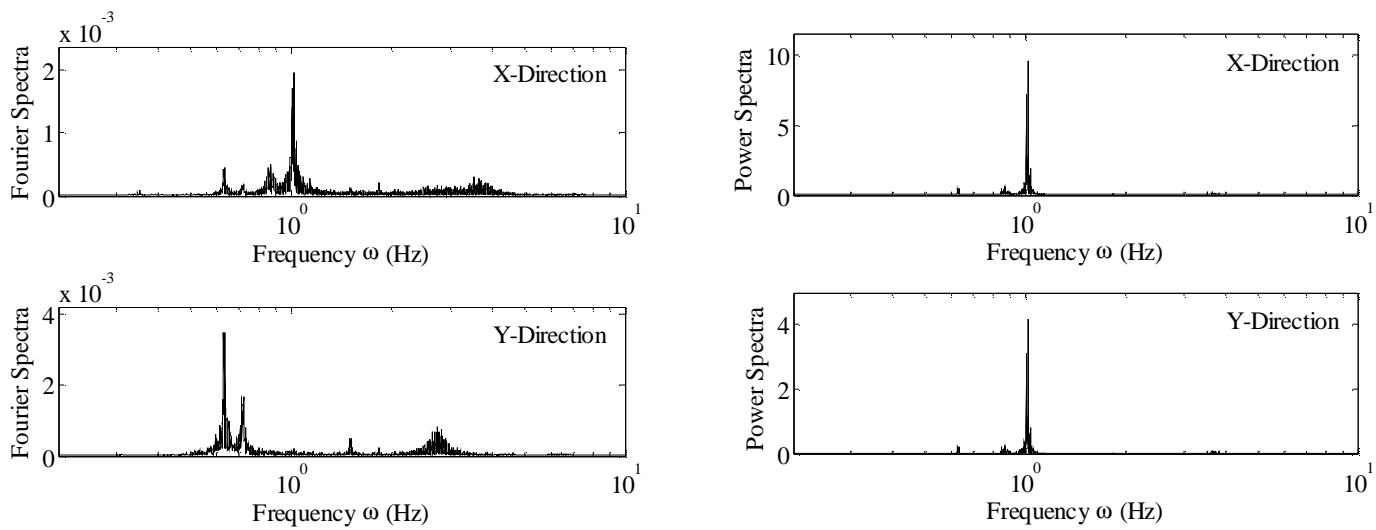

(c) the $28^{\text {th }}$ floor

Fig. 7 the Fourier Spectra and the Power Spectra

\section{Conclusions}

The structural modal parameter identification method under the ambient excitation was used to test the dynamic characteristics of 100-meter the fully-grouted reinforced-block masonry shear wall (FG-RMSW) structure. The test scheme was designed according to the characteristics of the structure. Three tests were carried out respectively when the structure was constructed on the $10^{\text {th }}$, the $18^{\text {th }}$, and the $28^{\text {th }}$ floor. The tests involved a transverse (X direction) translation and a longitudinal ( $\mathrm{Y}$ direction) translation, vertical translation and rotation around the $\mathrm{Z}$ axis. The structure used Block 290 for $1^{\text {st }}-12^{\text {th }}$ floors, Block 190 for $15^{\text {th }}-28^{\text {th }}$ floors, while the $13^{\text {th }}$ and the $14^{\text {th }}$ are the transition floors. The measuring points were arranged according to the characteristics of the structure. The test scheme and the measuring point arrangement in this paper can provide a reference for the dynamic tests of the structures similar to this one. Through the acquired test data, it is determined that the velocity time-history was relatively stable without showing an excessive fluctuation or pulse. So, it was suggested that the velocity time-history should be used as the analysis object. The frequency spectra 
analysis was carried out on the structure and the Fourier spectra at different heights were obtained after calculation. It was found that there were large peaks in the spectra, corresponding to some frequencies of the structure. Through calculation, the fundamental frequencies of the structure on the $10^{\text {th }}$, the $18^{\text {th }}$, and the $28^{\text {th }}$ floor, were obtained, namely $2.76 \mathrm{~Hz}, 1.18 \mathrm{~Hz}$ and $0.63 \mathrm{~Hz}$, respectively. The higher the height of the structure, the more abundant the spectral patterns are, and the more high-order modes can be displayed. It can be concluded that the dynamic characteristics of such structures can be obtained by means of the ambient vibration test method, which can provide experimental foundation for the dynamic characteristics analysis of high-rise reinforcement systems.

\section{Acknowledgements}

This research was financially supported by the National Natural Science Foundation of China (Grant No. 51608231 and No. 51678221), Project of Institute of Engineering Mechanics, China Earthquake Administration (Grant No.2017B16), Education Department project of Heilongjiang Province (Grant No.2016-KYYWF-0112) and the Natural Science Foundation of Heilongjiang Province (Grant No.LC2017025). The authors thank the staff of Key Laboratory of Earthquake Engineering and Engineering Vibration of China Earthquake Administration, Ministry of Education.

\section{References}

[1] Ren Weixin. Comparative analysis of ambient vibration system identification methods [J]. Journal of Fuzhou University (Natural Science), 2001, 29 (6): 80-86.

[2] Dora F, Mariella D, Nicola I G, et al. Ambient vibration testing, dynamic identification and model updating of a historic tower [J]. NDT\& E International, 2012, 47: 88-95.

[3] Sanghyun C, Sooyong P, Chang H, et al. Modal parameter identification of a containment using ambient vibration measurements [J]. Nuclear Engineering and Design, 2010, 240(3): 453-460.

[4] Eduardo N B, Carlos A S, Daniel A S. Structural assessment of the tower of the University of Coimbra by modal identification[J]. Engineering Structures, 2008, 30: 3468-3477.

[5] Ren W X, Obata M. Elastic-plastic seismic behavior of long span cable-stayed bridges [J]. Journal of Bridge Engineering, 1999, 4 (3): 194-203.

[6] Bao Xingxian. Modal parameters identification based on signal denoising under ambient excitation [J]. Journal of Vibration and Shock, 2014, 33 (21): 67-72.

[7] Wen Ruizhi, Zhou Zhenghua, Mao Guobin, et al. Ambient vibration test of the Wooden Tower in Ying County[J]. Earthquake Engineering and Engineering Vibration, 2006, 26 (4): 136-140.

[8] Xu Xiuzhong, Hua Hongxing, Chen Zhaoneng. Review of modal identification method based on ambient excitation [J]. Journal of Vibration and Shock, 2002, 21 (3): 1-6.

[9] Zhao Yan. Research on seismic behavior and dynamic testing of 100-meter reinforced-block masonry shear wall structures[D]. Harbin: Harbin Institute of Technology Doctor thesis, 2015: 133-149.)

[10] Ye Xijun, Yan Quansheng, Li Jian, et al. Modal identification and cable tension estimation of long span cable-stayed bridge based on ambient excitation[J]. Journal of Vibration and Shock, 2012, 31 (16): 157-163. 
[11]Yu Danjiang. Modal parameter identification of civil engineering structures-theory, implementation and application [D]. Fuzhou: Fuzhou University, 2005: 6-10, 32. 